УДК 343.14

\title{
Дьяконова В.В.
}

\section{- ЗНАЧИМОСТИ СИСТЕМЫ ПРИНЦИПОВ УГОЛОВНОГО СУДОПРОИЗВОДСТВА В АЛЬТЕРНАТИВНОЙ ФОРМЕ СУДЕБНОГО РАЗБИРATEЛЬCTВA}

\author{
Dyakonova V.V. \\ ON THE SIGNIFICANCE OF THE SYSTEM \\ OF PRINCIPLES OF CRIMINAL JUSTICE \\ IN AN ALTERNATIVE FORM OF TRIAL
}

\begin{abstract}
В данной статье исследуются пределы, реализация и значимость принципов в сокращенном порядке судебного разбирательства, предусмотренном гл. 40 УПК РФ. Закрепленная в главе 2 УПК РФ система принципов, призвана определять построение всех форм и стадий уголовного судопроизводства. Но в зависимости от особенностей отдельных процессуальных форм и стадий процесса пределы действия некоторых принципов могут быть ограничены. Обязательность соблюдения всех принципов уголовного судопроизводства при расследовании и рассмотрении уголовных дел презюмируется. Любое их несоблюдение или ограничение должно вести к признанию вынесенного по делу решения незаконным и его отмене. Для того чтобы определить законность принятого решения, следует определить пределы действия принципа, действие которого ставится под сомнение. В большой степени пределы действия принципа формируются особенностями процедуры расследования и рассмотрения уголовных дел.
\end{abstract}

Ключевые слова: особый порядок судебного разбирательства, сокращенное производство, принципы уголовного судопроизводства, пределы действия принципа, соблюдение принципов уголовного судопроизводства, причины несоблюдения или ограничения принципов.

This article examines the limits and implementation of the principles in the abbreviated procedure of judicial proceedings provided for in Chapter 40 of the Code of Criminal Procedure of the Russian Federation. The system of principles enshrined in Chapter 2 of the Criminal Procedure Code of the Russian Federation is designed to determine the construction of all forms and stages of criminal proceedings. But depending on the specifics of individual procedural forms and stages of the process, the limits of some principles may be limited. The obligation to comply with all the principles of criminal procedure in the investigation and consideration of criminal cases is presumed. Any failure to comply with them or limit them should lead to the recognition of the decision made in the case as illegal and its cancellation. In order to determine the legality of the decision taken, it is necessary to determine the limits of the operation of the principle whose operation is being questioned. To a large extent, the limits of the principle are formed by the peculiarities of the procedure for investigating and considering criminal cases.

Keywords: special procedure for judicial proceedings, reduced proceedings, principles of criminal procedure, limits of the principle, compliance with the principles of criminal procedure, reasons for non-compliance with or restrictions on the principles.

Следствием произошедших изменений в государстве и обществе явилось ре- формирование законодательства Российской Федерации, в том числе и уголовно- 
процессуального. Приведение уголовнопроцессуального законодательства России в соответствии с положениями Конституции РФ, международно-правовыми нормами не могло не отразиться на конструировании судебной процедуры рассмотрения уголовных дел. Появившиеся в данный период альтернативные процессуальные формы рассмотрения уголовных дел (например, рассмотрение уголовных дел с участием присяжных заседателей, производство по уголовным делам, подсудным мировому судье) существенно отличаются от обычного порядка их рассмотрения. Естественно, что вместе с этим изменились задачи и цель (назначение) уголовного процесса. В системе принципов уголовного судопроизводства также претерпели изменения, как по их количеству, содержанию, так и по пределам их действия на различных стадиях уголовного процесса. Принципы уголовного судопроизводства позволяют определить уровень защиты прав и свобод личности в уголовном судопроизводстве.

Если принципы уголовного судопроизводства должны определять построение всех его стадий, институтов, отдельных процедур (форм), то исходя из этого, можно сделать два вывода. Первый - о том, что определяющими уголовное судопроизводство являются все принципы, закреплённые в главе 2 УПК РФ и действуют в полном объёме на всех стадиях уголовного судопроизводства. Второй вывод - принципы уголовного судопроизводства в целом определяют построение всего уголовного процесса, но в зависимости от особенностей отдельных процессуальных форм и стадий процесса пределы действия некоторых принципов могут быть ограничены [1, с. 103]. На данное обстоятельство неоднократно указывалось в учебной и научной литературе. В. ловного процесса в полной мере действуют на стадии судебного разбирательства На стадии предварительного следствия и дознания некоторые из них не действуют или действуют в ограниченных рамках.» [2. с.75]. В таком случае возникает резонный вопрос о правомерности установления таких ограничений, а также о субъектах их устанавливающих.

Считаю, что разрешение данного вопроса имеет не только теоретическое, но и практическое значение для рассмотрения уголовных дел, с точки зрения вынесения законных решений, а также неукоснительного соблюдения прав и законных интересов участников уголовного процесса.
В этой связи представляется правильным утверждение о том, что прицепы уголовного судопроизводства, в своей взаимосвязи, образуют систему, каждое звено которой характеризует отдельную сторону или грань уголовного процесса [3, c.74]. Рассмотрение вопроса об официальном закреплении пределов действия принципов уголовного судопроизводства представляется актуальным для особого порядка принятия судебного решения при согласии обвиняемого с предъявленным ему обвинением (глава 30 УПК РФ), так как данный порядок рассмотрения уголовных дел судом I инстанции является альтернативным, абсолютно новым для отечественного уголовного процесса и до конца не исследованным. Поскольку данный порядок является сокращенным производством, то первостепенным является вопрос о гарантиях соблюдения прав участников уголовного процесса в этом порядке.

Несмотря на то, что принципам посвящены многие работы видных учёных-специалистов [4, с. 104-105], на данную проблему в настоящее время уже обращали внимание в своих публикациях учёныепроцессуалисты: Л.В. Головке, И.Л. Петрухин, И.Б. Михайловская, О.В. Волколуп и юристы-практики - судья Верховного Суда РФ В. Демидов, старший помощник прокурора Республики Башкортостан А. Халиков, судья Гатчинского городского суда П. Михайлов. В их работах в той или иной степени затрагивается вопрос о пределах действия принципов уголовного судопроизводства при рассмотрении дел в порядке особого производства, регламентированного главной 40 УПК РФ. Однако полагаю, что ставить точку в исследовании пока преждевременно, тем более, что мнения по данному вопросу высказываются неоднозначные и даже прямо противоположные. А. Халиков, например, абсолютно обоснованно считает важным выяснение вопроса о соблюдении принципов уголовного судопроизводства в особом порядке судебного разбирательства, особенно принципа состязательности сторон, которые непосредственно относятся к судебной стадии процесса. Также он считает, что исходя из требований законности, принцип состязательности, как и все другие, не может быть исключен при особом порядке судебного разбирательства [5, с. 64]. Противоположной точки зрения придерживается П. Михайлов, который убеждён, что «идея введения сделки в уголовный процесс не соответствует общим принципам в нашем обществе, а также противоречит 
основным правам и свободам граждан, предусмотренным Конституцией РФ». Свой вывод он основывает на сравнении с американскими сделаками о признании вины, ссылаясь на то, что «многие в США считают сделки позором для правосудия...» [6, с. 37].

Обязательность соблюдения всех принципов уголовного судопроизводства при расследовании и рассмотрении уголовных дел презюмируется и поддерживается Верховным Судом РФ. Любое несоблюдение или ограничение принципиальных положений должно вести к признанию вынесенного по делу решения незаконным и его отмене. Думается, что для того, чтобы определить законность принятого решения, следует определить пределы действия того принципа, о нарушении которого заявляется кем-либо из участников процесса. В данном случае необходимо определить причины его несоблюдения или ограничения. На мой взгляд, таких причин может быть две - субъективная и объективная. Субъективная причина заключается в прямом нарушении должностным лицом, в производстве которого находится уголовное дело, норм действующего УПК ФР, закрепляющих содержание и действие того или иного принципа. Она зависит исключительно от воли субъекта, принимающего решение по уголовному делу. Установление субъективного характера нарушения закона влечёт отмену вынесенного по делу решения. Объективная причина несоблюдения или ограничения принципов уголовного судопроизводства кроется в отсутствии чётких границ, пределов их действия. Таким образом, если действие рассматриваемого принципа ограничивается толкованием его содержания в конкретной стадии уголовного процесса или при выполнении определённых процессуальных действий, то ни о каком нарушении и незаконном ограничении прав участников не может быть и речи [7, c. 106].

Анализируя принципы уголовного судопроизводства, И.Б. Михайловская специально акцентирует внимание на вопросе о сфере их действия: во всех ли стадиях действуют принципы или только в некоторых. Она отмечает, что принцип не может полностью утрачивать своё значение в любой из стадий процесса. Формы его действия могут быть различными, поскольку они испытывают на себе влияние частной задачи, стоящей перед конкрет- ной стадией, но, тем не менее, принцип, если он не носит декларативный характер, всегда будет неким ориентиром в выборе средств достижения желаемой цели [8, с. 117-118].

Отсюда следует, что данное утверждение в полной мере относится и к порядку рассмотрения уголовных дел, предусмотренному главой 40 УПК РФ, и имеет для него особое значение.

На различие пределов действия определённых принципов уголовного судопроизводства от стадии к стадии в зависимости, например, от изменения состава должностных лиц, их правового статуса, указывает О.В. Волколуп, подчёркивая, таким образом, что от совокупности принципов, действующих в той или иной стадии, в большей степени зависит особенности её процедуры [9, с. 10].

Известно, что среди различных научных взглядов существует мнение, что при рассмотрении уголовных дел в порядке особого производства при согласии обвиняемого с предъявленным ему обвинением (гл. 40 УПК РФ) нарушаются или вообще утрачивают своё действие многие принципы уголовного судопроизводства и что такого рода нарушения возникают в силу самой сущности данного судебного порядка, которая изначально предполагает вынесение судом незаконного решения. Рассматривая, например, пределы действия, принципа состязательности, считаю, что в сокращенном производстве действует данный принцип действует, но действует усечённо, а пределы его действия зависят от особенностей судебного следствия [10, с. 128]. Несмотря на это, за участниками судебного разбирательства сохраняются процессуальные равенство прав и соблюдаются общие требования уголовно-процессуального кодекса при исследовании доказательств в соответствии с теми изъятиями, которые предусматривает закон (ст. 316 УПК РФ). Аналогично можно рассмотреть реализацию в данном производстве принципа охраны прав и свобод человека и гражданина, а равно и других принципов.

Думается, что указанный пример является неплохим доказательством неравномерности пределов действия даже одного принципа в рамках уголовного судопроизводства, но его первостепенной значимости для сокращенной процессуальной формы рассмотрения уголовных дел.

\section{3}

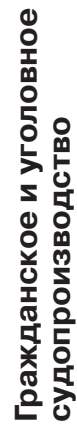

Литература

1. Дьяконова В.В. Особый порядок судебного разбирательства при согласии 
обвиняемого с предъявленным обвинением. Диссер. на соискание ученой степени кандидата юридических наук. Екатеринбург, 2005 г. С.103.

2. Уголовный процесс: учебник для вузов. Под ред. В.П. Божьева. 2-е изд., испр. и доп. М.: Спарк, 2000. С. 75.

3. Уголовный процесс: учебник для вузов. Под ред. В.П. Божьева. 2-е изд., испр. и доп. М.: Спарк, 2000. С. 74.

4. Дьяконова В.В. Особый порядок судебного разбирательства при согласии обвиняемого с предъявленным обвинением. Диссер. на соискание ученой степени кандидата юридических наук. Екатеринбург, 2005 г. С. 104-105.

5. Халиков А. Вопросы, возникающие при особо порядке судебного разбирательства // Российская юстиция. 2003. № 1. С. 64.

6. Михайлов П. Сделки о признании вины - не в интересах потерпевших // Российская юстиция. 2001. № 5. С. 37.

7. Дьяконова В.В. Особый порядок судебного разбирательства при согласии обвиняемого с предъявленным обвинением. Диссер. на соискание ученой степени кандидата юридических наук, 2005 г. С.106.

8. Михайловская И.Б. Цели, функции и принципы российского уголовного судопроизводства (уголовно-процессуальная форма). М.: ТК Велби. Изд-во Проспект, 2003. С. 117-118.

9. Волколуп О. В. Система уголовного судопроизводства и проблемы ее совершенствования. СПб., 2003. С. 10.

10. Дьяконова В.В. Особый порядок судебного разбирательства при согласии обвиняемого с предъявленным обвинением. Диссер. на соискание ученой степени кандидата юридических наук. Екатеринбург, 2005 г. С.128.

\section{References}

1. D'yakonova V.V. Osobyy poryadok sudebnogo razbiratel'stva pri soglasii obvinyayemogo s pred"yavlennym obvineniyem. Disser. na soiskaniye uchenoy stepeni kandidata yuridicheskikh nauk. Yekaterinburg, 2005 g. S.103.

2. Ugolovnyy protsess: uchebnik dlya vuzov. Pod red. V.P. Bozh'yeva. 2-ye izd., ispr. i dop. M.: Spark, 2000. S. 75.

3. Ugolovnyy protsess: uchebnik dlya vuzov. Pod red. V.P. Bozh'yeva. 2-ye izd., ispr. i dop. M.: Spark, 2000. S. 74.

4. D'yakonova V.V. Osobyy poryadok sudebnogo razbiratel'stva pri soglasii obvinyayemogo s pred"yavlennym obvineniyem. Disser. na soiskaniye uchenoy stepeni kandidata yuridicheskikh nauk. Yekaterinburg, 2005 g. S.104-105.

5. Khalikov A. Voprosy, voznikayushchiye pri osobo poryadke sudebnogo razbiratel'stva // Rossiyskaya yustitsiya. 2003. № 1. S. 64.

6. Mikhaylov P. Sdelki o priznanii viny - ne v interesakh poterpevshikh // Rossiyskaya yustitsiya. 2001. № 5. S. 37.

7. D'yakonova V.V. Osobyy poryadok sudebnogo razbiratel'stva pri soglasii obvinyayemogo s pred"yavlennym obvineniyem. Disser. na soiskaniye uchenoy stepeni kandidata yuridicheskikh nauk, 2005 g. S.106.

8. Mikhaylovskaya I.B. Tseli, funktsii i printsipy rossiyskogo ugolovnogo sudoproizvodstva (ugolovno-protsessual'naya forma). M.: TK Velbi. Izd-vo Prospekt, 2003. S. 117-118

9. Volkolup O. V. Sistema ugolovnogo sudoproizvodstva i problemy yeye sovershenstvovaniya. SPb., 2003. S. 10.

10. D'yakonova V.V. Osobyy poryadok sudebnogo razbiratel'stva pri soglasii obvinyayemogo s pred"yavlennym obvineniyem. Disser. na soiskaniye uchenoy stepeni kandidata yuridicheskikh nauk. Yekaterinburg, 2005 g. S.128.

ДьяКОНОВА Виктория Викторовна, кандидат юридических наук, доцент, кафедра судебной деятельности и уголовного процесса, ФГБОУ ВО “Уральский государственный юридический университет". Россия, 620137, г. Екатеринбург, ул. Комсомольская, 21. E-mail: up@usla.ru, vdyakonova72@ mail.ru; Доцент, кафедра права ИНФО УрФУ, ФГАОУ ВО «УрФУ имени первого Президента России Б.Н. Ельцина», 620002, Уральский Федеральный округ, Свердловская область, Екатеринбург. ул.Мира, 19. E-mail:kaf_prava@ mail.ru

DYAKONOVA Victoriya Victorovna, Candidate of Legal Sciences, Associate Professor, Department of Judicial Activity and Criminal Procedure, Ural State Law University, Russia, 620137, Ekaterinburg, Komsomolskaya St., 21. E-mail: up@usla.ru; Associate Professor, Department of Law INFO UrFU, Federal State Educational Institution "UrFU named after the first President of Russia B. N. Yeltsin", 620002, Ural Federal District, Sverdlovsk region, Yekaterinburg. Mira str., 19. E-mail: kaf_prava@mail.ru 